\title{
A (DI)GESTÃO DO RISCO NUCLEAR NA FRANÇA: O CASO DAS COMISSÕES LOCAIS DE INFORMAÇÃO*
}

Gláucia Silva

\section{Introdução}

O presente artigo traz uma análise sobre certa forma de "participação" de cidadãos, encontrada na França, decorrente de uma iniciativa governamental que instituiu comissões compostas por representantes das usinas nucleares e da população em geral para a troca de informações sobre o funcionamento dessas fábricas: trata-se das Comissões Locais de Informação (CLI).

Dois aspectos são fundamentais para qualificar esse tipo de fórmula participativa: o primeiro é que tais comissões são produto tanto de uma mobilização estatal da sociedade, tendo sido instituídas por ato do Primeiro Ministro francês Pierre Mauroy em 1981, quanto de uma auto-organização da sociedade para fiscalizar o Estado, na medida em que a iniciativa de sua criação respondeu à demanda de movimentos contestatórios que nos anos 1970 se opuseram à construção de centrais nucleares e clamavam pela formação de comissões de vigilância. Além disso, seus membros reformulam e ampliam as funções formais, extrapolando a simples troca de informações.

O segundo aspecto da especificidade dessas comissões é que sua criação atesta a existência de algo que nem sempre foi admitido pelos responsáveis do Programa Nuclear francês, isto é, a presença de um risco associado à atividade tecnológica desenvolvida nas Centrais Nucleares.

O principal argumento desse trabalho é que tais associações, criadas com o objetivo de democratizar o acesso às informações sobre a operação dos reatores, podem ser entendidas, por um lado, como um meio de gerir a desconfiança (nutrida pela população para com a central), segundo uma "etiqueta" própria (Elias 1990; Leite Lopes et alii 2004) $i^{1}$ dessa forma, um espaço criado com o intuito básico de informar - ao qual não se atribuiu qualquer poder decisório - ganhou, entretanto, uma feição específica na qual suspeições sobre se a usina opera ou não dentro das normas podem 
ser manifestadas e esclarecidas sem evocar um antagonismo que inviabilize a comunicação. Por outro lado, podem ser também entendidas como um espaço para a gestão do risco tecnológico (proporcionado pela central à circunvizinhança).

A mencionada etiqueta, adotada pelos participantes das CLI, assegura o "engajamento" ou o "compromisso" (cf. Boltanski \& Thévenot 1991) em prol de um "bem comum", a sociedade francesa. Ela prescreve, como se verá na análise da dinâmica das CLI desenvolvida a seguir, o comedimento na manifestação da desconfiança em relação ao bom funcionamento da Central e, contrariando a tendência de seus participantes antinucleares, reprime a explicitação do conflito que só pode se manifestar na forma de um debate técnico, um "duelo verbal", em que as armas mais poderosas são os laudos técnicos. Também aqui é indispensável a remissão a Elias:

A tarefa de um estado democrático consiste em regular a resolução de conflitos dos mais importantes grupos de uma sociedade através de instituições especiais que facilitam os debates entre grupos contrários e sua resolução. A disputa é limitada às formas não violentas de luta travada, em primeiro lugar, na forma de discussão ou duelo verbal (grifo meu), cuja resolução depende de todos os participantes aderirem a certas regras (1997:262).

A gestão técnica do risco nuclear - aqui entendida como o conjunto de decisões tomadas a propósito da nomeação do risco, sua classificação e a adoção de medidas preventivas ou mitigadoras - é aceita, mesmo que marginalmente, pelos membros da CLI quando fazem atividades como a distribuição de pastilhas de iodo e a divulgação de práticas a serem seguidas em caso de anormalidade na usina. A CLI passa a significar então para a Central um meio de sensibilização da população em relação a certos procedimentos preventivos.

Tanto a assunção de uma etiqueta que - ao fechar o espaço das comissões para manifestações contrárias à presença das centrais (como fazem os movimentos contestatórios) — viabiliza o compromisso das partes representadas na CLI, quanto a iniciativa de assumirem tarefas preventivas do risco, sem esperarem solicitação ou consentimento da Central, evidenciam, conforme ilustra o chiste do título, o pragmatismo dos participantes das CLI, que "digerem" o risco, assimilando-o ao cotidiano.

Uma discussão conceitual sobre o fascinante tema dos "riscos tecnológicos", tratado através da ótica das ciências sociais, foi feita em outros trabalhos individuais (Silva 1999a,1999b), nos quais as idéias de dois autores - Mary Douglas e Ulrich Beck - foram contrastadas, e também em obras coletivas 
(Leite Lopes et alii 2000, 2004). Tentar retomá-la dentro dos limites deste artigo causaria prejuízos à sua densidade. Mas é relevante esclarecer que os mencionados autores têm aprofundado suas teorias iniciais em trabalhos mais recentes (por exemplo, Beck 1995, 2003) sem alterarem, contudo, a essência das mesmas.

É também importante mencionar que uma das fontes de inspiração para o argumento do presente artigo é, sem dúvida, emprestada de Douglas que mostrou ser o "risco" uma construção coletiva, cultural e politicamente embasada (Douglas \& Wildawski 1982; Douglas 1992). No entanto, seu relativismo incondicional não é aqui endossado, nem sua conclusão de que a visão segundo a qual o mundo estaria mais perigoso é antes fruto de uma ideologia da segurança do que propriamente da existência de riscos inéditos.

Entendo "risco" como uma categoria referida a um sistema classificatório; assim, ao falarmos de risco, estamos necessariamente falando da representação de uma ameaça - real ou não - e, portanto, de sua construção social. Ao assumirem as funções de gestão de desconfianças e de contribuírem para a gestão do risco nuclear, tais comissões tornam-se parte importante no processo de construção social do risco por três motivos básicos: (a) conforme acima mencionado, sua existência atesta a presença de uma ameaça; (b) nelas as representações sobre o que é perigoso ou arriscado do ponto de vista da população vizinha às usinas nucleares podem ser confrontadas com aquelas partilhadas pelos técnicos da empresa; (c) finalmente, seus membros criam mecanismos de vigilância sobre o risco.

Dessa maneira, o que chamo "risco" é produto de todo um processo de nomeação, institucionalização e verificação que pode sofrer flutuações ao longo do tempo - e aqui também a presente análise se afasta da rigidez da tipologia de Douglas \& Widawski (cf. 1982). A própria mudança de visão da sociedade francesa em relação ao Programa Nuclear Francês é um exemplo dessa possibilidade de alteração na concepção de um risco, como deverá ficar ilustrado ao final do artigo. Chateauraynaud e Torny (1999) elaboram uma gramática de tal processo, identificando diversas configurações intercambiáveis que vão da função de vigilância (na qual podemos localizar as CLI) até o procedimento de crise, evidenciando o duplo caráter do processo de construção social do risco, que é histórico ao mesmo tempo em que obedece a uma conformação básica.

Contrariamente à visão de Mary Douglas, Ulrich Beck afirma que os riscos tecnológicos não são comparáveis a outros perigos, caracterizando o aparecimento de um tipo específico de sociedade — a "de riscos" — numa nova faceta da modernidade - "a reflexiva" — em que os valores e os pressu- 
postos que legitimaram o processo de industrialização são questionados (Beck 1992a, 1992b, 1995). Com ele, avalio que os riscos tecnológicos apresentam mesmo uma faceta inédita da acumulação capitalista, ganhando uma conotação sociológica bastante sui generis; entretanto, filiar o presente trabalho a tal matriz teórica, que inclui um diagnóstico sobre uma "nova época" (Beck 1995:2) na qual ingressariam as diversas sociedades industrializadas, obrigaria a diversos tipos de ressalvas e desviaria o artigo de seu intento.

Em contrapartida, consideramos a referência à sociologia de Boltanski sua teoria das "cidades" elaborada com Thévenot (1991) e retomada com Chiapello (1999), e uma profunda e pertinente análise do sistema capitalista — como extremamente adequada à compreensão da sociedade francesa atual, incluindo o aspecto de como elabora a gama de riscos trazidos por seu amplo Programa Nuclear.

\section{Municipalidade e Central Nuclear no contexto francês}

"O nuclear" é uma expressão que designa todo um conjunto de atividades relativas ao processamento de substâncias como o urânio, material cujos átomos podem ser divididos, gerando calor e radioatividade. Tal expressão está presente no discurso de técnicos e leigos que assim transformam a qualidade de certos elementos químicos em uma entidade ou, ainda conforme os termos de seus atores, em um "mundo". O "mundo nuclear", na França, compõe-se de uma miríade de instituições civis e militares dedicadas à pesquisa e à indústria.

As usinas nucleares, que garantem na França cerca de $80 \%$ da produção total de energia elétrica, são componentes da indústria civil nesse "mundo". Após ter sido usado como combustível pelas usinas, o urânio pode ser utilizado para a fabricação de armas atômicas. A implantação das instalações destinadas à fabricação de artefatos bélicos e a construção das usinas acontecem envoltas em uma aura de "segredo".

As centrais nucleares francesas começaram a ser construídas a partir dos anos 1970, manifestamente como resposta à crise do petróleo, sem o prévio consentimento da população, forma que é hoje sentida como "antidemocrática", conforme se verá adiante. Embora o "segredo" (incluindo-se a forma "autoritária" de implantação) que envolve a construção das centrais e o "perigo" a elas atribuído não sejam exclusividades suas, as centrais nucleares reúnem condições especiais para serem depositárias preferenciais de tais quesitos, como mostram Pollak e Nelkin (1981), Chiva (1970) e Zonabend (1989). 
Na França, há ainda pelo menos dois aspectos que fazem da mencionada atividade algo sui generis, a saber : os responsáveis pela decisão da implantação das Centrais são vistos como componentes de um corpo técnico, com forte expressão política e econômica, os quais se manifestam através de um "poderoso" lobby, o "lobby nuclear". Considera-se ainda que esse "mundo", que funciona de forma "autônoma" e "secreta", cujo acesso ao cidadão comum é difícil ou impossível, constitui, conforme opinião de um cientista ${ }^{2}$ entrevistado por uma emissora de televisão, ${ }^{3}$ "um mundo à parte" no seio da sociedade francesa.

Numa tentativa de abrir esse "mundo nuclear secreto" ao questionamento público, o Governo Mitterrand (1981-1995) criou comissões - Comissões Locais de Informação (CLI) — para a divulgação à população das informações relativas às atividades nucleares.

As centrais elétricas nucleares na França pertencem à empresa estatal Eletricidade de França ${ }^{4}$ (doravante EDF). A Autoridade de Segurança Nuclear (ASN), comumente referida simplesmente por Autoridade Nuclear, que também é uma instituição da administração pública, ${ }^{5}$ é a responsável pela fiscalização das atividades nucleares civis em todo o território nacional. A função dos inspetores da Autoridade Nuclear é verificar as condições de trabalho nas centrais presentes em sua região de atuação.

Normalmente as usinas são estabelecidas em cidades pequenas, como Nogent-sur-Seine (atualmente com cerca de 6 mil habitantes) e Fessenheim (hoje em dia com perto de 2 mil habitantes). Ao chegar à cidade, a EDF adianta à administração local parte do valor do pagamento de impostos que fará a partir do funcionamento da usina. O dinheiro é utilizado na ampliação da infra-estrutura existente. A municipalidade então constrói escolas, prédios residenciais e postos de atendimento médico para recepcionar os trabalhadores da central.

Os impostos pagos a partir do início de sua operação representam uma percentagem importante do orçamento das administrações municipais, e as pequenas cidades que hospedam centrais nucleares passam a dispor de uma receita considerável, conforme conta o administrador municipal (maire) da cidade de Nogent-sur-Seine:

É bem verdade que a cidade foi muito afetada pela implantação da central nuclear porque chegaram aqui entre 2 mil e 2,5 mil pessoas para o canteiro de obras. Atualmente são 700 pessoas que lá trabalham permanentemente. A central de Nogent começou a produzir eletricidade em 1987, mas o canteiro começou em 1977 [...]. Ela, além de trazer mudanças socioeconômicas, trouxe também financeiramente vantagens para Nogent porque a EDF, como todo 
o industrial que se instala, paga dois impostos à municipalidade, que são os impostos predial e profissional (taxe foncière e taxe professionel). Nogent, que é uma pequena cidade de 6 mil habitantes, tem um orçamento de uma cidade de 15 ou 20 mil habitantes (Mr. Ancelin).

A presença da usina não é apenas importante do ponto de vista econômico, mas também tem conseqüências no plano político, como narra ainda Mr. Ancelin afirmando que sua cidade, mesmo com poucos habitantes, graças à central, pode abrigar uma subprefeitura: ${ }^{6}$

A cidade vizinha, de Romily-sur-Seine, que é mais populosa que Nogent, com 15 mil habitantes, tentou ficar com a nossa subprefeitura, mas nós não deixamos, porque a subprefeitura já existe aqui há muito tempo. Mesmo que Romily seja maior, o fato de a Central estar localizada aqui faz com que a subprefeitura esteja aqui [...] Ter uma subprefeitura confere certo peso político, certa notoriedade à cidade.

\section{As Comissões Locais de Informação (CLI)}

\section{Retrospectiva}

Conforme a circular ministerial ${ }^{7}$ do Primeiro Ministro Pierre Mauroy (1981-1984), uma Comissão Local de Informação pode ser criada para cada instalação nuclear na França. ${ }^{8}$ Existem ao todo 30 CLI, aí incluídas comissões análogas intituladas diferentemente, mas que têm a mesma função junto a diversos estabelecimentos nucleares e não só centrais nucleoelétricas. Essas comissões acompanham as atividades de 19 centrais e outras instalações, ${ }^{9}$ e cada uma delas tem sua própria história e maneira de trabalhar.

A circular ministerial, dispositivo do Poder Executivo, garante o status formal das Comissões Locais de Informação, mas não tem o peso de uma lei. É voz corrente, entretanto, que esse status formal foi uma resposta a iniciativas dos chamados movimentos antinucleares (ou simplesmente "anti"), surgidos na década de 1970, conforme foi dito anteriormente. Na cidade de Fessenheim, o movimento "anti" manteve uma greve de fome e, atualmente, pessoas entrevistadas de outras regiões atribuem tal "radicalismo" à vizinhança dos "verdes alemães". Em Fessenheim, os manifestantes tiveram sucesso ao implantar, em 1977, a primeira comissão - que ainda hoje guarda o nome de Comissão Local de Vigilância - para acompanhamento das atividades da central: 
Os opositores formaram um comitê que tinha por objetivo obter do Conselho Geral a permissão de criar uma comissão que teria acesso aos documentos da central, o que, na época, era dificilmente conseguido; os documentos eram dificilmente colocados à disposição pela EDF. O movimento se reforçou com uma greve de fome que durou 10 dias. O Conselho Geral acabou por autorizar o funcionamento da comissão que, desde 1977, é muito ativa se compararmos com outras CLI. Embora as comissões propostas pela circular sejam chamadas de comissões de informação, a de Fessenheim guardou seu nome de origem: Comisssão Local de Vigilância (Mr. Schmitt, presidente da CLS de Fessenheim e conselheiro geral).

Como um passo além da determinação da circular, dezenove anos após a sua assinatura pelo primeiro ministro Mauroy, surge a ANCLI (Associação Nacional das CLI), criada em 2000 por um grupo de presidentes de algumas comissões locais que imediatamente convidaram à adesão todos os outros; hoje em dia, dela fazem parte 15 presidentes. A Associação tem por objetivo a troca de informações entre as comissões locais, projetando em nível nacional as questões que surgem em cada uma delas, e também o incentivo a iniciativas locais, como o recurso à contra-expertise.

A ANCLI organiza colóquios anuais, publica uma revista chamada significativamente de Declic $^{10}$ e, como as CLI, promove reuniões de estudos e viagens a vários sítios nucleares. Essa prática, entre outros efeitos, aproxima os presidentes de CLI, que antes encontravam-se apenas uma vez a cada ano nas Conferências dos Presidentes de CLI promovidas pela Autoridade Nuclear. ${ }^{11}$

Uma importante demanda da ANCLI é a votação da lei sobre a transparência nuclear, aguardada há anos pelos componentes das CLI, que defina regras para seu orçamento. As CLI, como a ANCLI, são mantidas pela própria ASN e também pelas administrações municipais e pelos conselhos gerais. Um orçamento regulamentado por lei daria mais autonomia e independência às comissões.

\section{Composição e funcionamento das CLI}

As CLI são compostas por políticos locais (administradores das cidades próximas à Central - maires - e os conselheiros), representantes do Estado na Região (préfet e sous-préfet), representantes de sindicatos e associações diversas - de consumidores, de proteção ao meio ambiente, de profissionais etc. - e outras pessoas, cujas presenças sejam consideradas importantes, convidadas pelo presidente da CLI.

Em uma entrevista, o representante "anti" na CLI de Nogent-sur-Seine comentou em tom crítico tratar-se de uma comissão de "notáveis" e não 
"de gente comum". É visível a preocupação de se convidar para integrá-la pessoas que sejam "representativas" de associações comerciais/profissionais ou, ainda, que sejam portadoras de algum saber considerado relevante, tais como cientistas, médicos e professores. Além disso, na CLI de Nogent-surSeine, que possui 114 membros cadastrados, ${ }^{12}$ há um número bem maior de prefeitos e conselheiros municipais (66) do que de representantes das associações civis (26); há ainda 10 representantes da central e da Autoridade Nuclear e 12 funcionários públicos ligados a órgãos de prestação de serviços (como bombeiros, policiais, chefe da emergência médica, da estação de trem etc). Dessa forma, ela parece reunir a "elite local" e pessoas que ocupam postos úteis para um momento de emergência.

Quem escolhe o presidente da CLI é o representante do Estado na Região (préfet). O número de participantes varia enormemente; por exemplo, a CLI de Nogent-sur-Seine possui mais de uma centena de membros, como já foi dito, enquanto em Fessenheim, 30 membros integram a comissão. Conforme observei nas duas assembléias da CLI de Nogent-sur-Seine às quais estive presente, a reunião desenrola-se em um clima formal. A audiência participa após cada exposição, ou seja, depois da apresentação dos relatórios da EDF e da Autoridade Nuclear, no tempo reservado às questões. O presidente da CLI (que é também administrador municipal de Nogent-sur-Seine) dirige a assembléia; a seu lado, na mesa que preside a reunião, ficam os funcionários da EDF, da ASN e também o representante do Estado.

Durante as assembléias, que ocorrem em geral duas vezes por ano, e duram normalmente duas horas e meia, os representantes da EDF narram os acontecimentos importantes vividos pela central ao longo do ano ou do semestre, conforme a pauta, e o inspetor da ASN discorre sobre o que observou durante as inspeções-surpresa que empreendeu na central em questão. A EDF e a Autoridade Nuclear são as grandes protagonistas das assembléias, apresentando seus relatórios e respondendo a perguntas dos presentes. Portanto, as assembléias da CLI são momentos em que os engenheiros da EDF e os inspetores da Autoridade Nuclear têm suas informações postas à prova, bem como sua postura imparcial de nada esconderem, caso alguma falha ou evento anormal tenha sido observado no funcionamento da usina.

A CLI de Nogent-sur-Seine possui também um pequeno comitê, composto por seis membros, que se reúnem mensalmente para a leitura e a discussão dos documentos enviados pela Central. Um engenheiro da EDF é destacado para acompanhar parte da reunião desse comitê e dar as explicações solicitadas. Sua composição é bem diferente daquela da assembléia ordinária, porque nela só há representantes das associações e de sindicatos, sob a coordenação de um auxiliar do maire, sem a participação de outros 
administradores ou políticos profissionais. Esse dispositivo não é encontrado na grande maioria das CLI.

Como foi anteriormente comentado, as CLI realizam atividades para a formação de seus membros e da população em geral, a exemplo de Nogent e Fessenheim que, entre as duas assembléias anuais, organizam conferências sobre temas ligados ao "nuclear" e visitas a outras usinas e a diversos sítios nucleares.

Assim como a história e a composição das CLI variam de uma para outra, sua capacidade de ação também varia. Há comissões reconhecidamente mais "ativas" e mais "críticas" que outras, segundo critérios partilhados por seus próprios participantes; mas estas não são a maioria. A CLI mais antiga e que deu origem à circular, a de Fessenheim, é ainda hoje considerada a mais atuante.

A combatividade de uma CLI está ligada à motivação dos maires e de outros políticos profissionais para dela fazerem um instrumento de investigação em relação às centrais. Se os representantes eleitos não se mostram preocupados em obter tais informações, o funcionamento da CLI cai na pura formalidade; o mesmo pode ser dito quanto ao papel do representante da Autoridade Nuclear na reunião que, apresentando um relatório mais crítico, pode despertar o interesse dos presentes e instigá-los a maiores investimentos sobre o funcionamento da usina.

Um terceiro ingrediente de grande importância é a presença dos "anti", os antinucleares, como membros da CLI e o espaço de atuação a eles conferido. Os "anti" não aprovam a existência das Centrais e colocam freqüentemente questões políticas e técnicas que outros membros não ousariam. Zonabend (1989) narra que na região do Contentin, à época em que fez sua pesquisa, havia oito "anti" conhecidos de todos. Eles eram referidos como a garantia de que alguém se preocupava com o bem-estar da população que, por outro lado, se mantinha silenciosa, sem iniciativa para interpelar a central, temendo represálias da empresa que garante boa parte dos empregos na cidade.

Membros da CLI de Nogent, também entrevistados, comentaram que as reuniões são mais animadas quando o "anti" está presente, já que normalmente não há discussões durante as assembléias.

\section{As CLI e o Estado francês}

Um importante efeito da criação e do funcionamento das CLI é a aproximação entre este grupo de representantes da população, que se mobiliza e investe parte de seu tempo para a construção deste espaço associativo, e os representantes do Estado francês. 
Tal aproximação pode ser ilustrada pela presença do Préfet ou do Sous-prefet em suas assembléias. Além disso, alguns presidentes das CLI vão várias vezes por ano à capital francesa, onde participam de reuniões na sede da Autoridade Nuclear.

Nas já mencionadas assembléias anuais dos presidentes de CLI, podem ser vistos "altos funcionários" do Estado francês, incluindo o presidente da Autoridade Nuclear e os representantes ministeriais, como a própria subministra da Indústria que, impossibilitada de ir à decima quinta reunião com os presidentes de CLI, enviou uma gravação com um pronunciamento feito especialmente para a ocasião. Após a criação da ANCLI, seu presidente passou a ser convidado pela Autoridade Nuclear a integrar a mesa dessa reunião que, nos treze anos anteriores, havia sido composta apenas por representantes do "mundo nuclear civil" institucional, isto é, a própria Autoridade Nuclear e a EDF. Por outro lado, a Autoridade Nuclear e a EDF são convidadas a participar dos Colóquios organizados pela ANCLI. ${ }^{13}$ O contato direto com a chamada "hierarquia estatal" abre a possibilidade de mudança na relação com o "mundo nuclear" e na visão segundo a qual é "um mundo à parte".

O exercício da construção dessas comissões também ilustra o desdobramento do Estado francês como empresário (EDF) e como regulador das atividades industriais (Autoridade Nuclear). Na França, a existência de um monopólio estatal da produção elétrica e, nele, a escolha da alternativa nuclear, impõe dificuldades para uma atuação "neutra", como pretendem os promotores das atividades nucleares, bem como o próprio ideário da administração estatal.

Em trabalhos de sociologia de organização de empresas (cf. Bourrier 1999), é constante a referência encontrada na França à "endogamia" dos órgãos de produção e inspeção das atividades nucleares, enquanto nos Estados Unidos são apontados como um modelo a ser seguido neste plano. Lá os empresários e os inspetores nucleares, ou seja, quem promove a atividade nuclear e quem inspeciona as usinas para avaliação do cumprimento das normas de funcionamento, pertencem a instituições diferentes. A "endogamia" francesa foi também criticada ao longo de uma entrevista feita com uma cientista, a professora Monique Sené, pesquisadora durante 50 anos no CNRS em física nuclear e física de partículas, e presidente do Grupo de Cientistas para a Informação sobre a Energia Nuclear — GSIEN, fundado por ela e seu marido em 1976. Bastante respeitada no meio, tanto pelos "anti" quanto pelos "pró", é freqüentemente convidada para reuniões organizadas pelas CLI, ANCLI e Autoridade Nuclear. Em entrevista, argumentou que engenheiros com função de produção recebiam como inspetores outros 
engenheiros, não raro colegas das escolas politécnicas, formadoras da elite administrativa francesa.

Além disso, verifica-se que a distinção entre cientistas/engenheiros pró-nuclear e cientistas/engenheiros anti é homóloga à outra: cientistas/ engenheiros formados pelas politécnicas e cientistas/engenheiros formados nas universidades (cf. Bourdieu 1982:206). A supracitada cientista é um exemplo de que esta correlação é fato; entendendo sua postura crítica em relação ao Programa nuclear francês, indaguei se ela se formara em escola politécnica. Ela sorriu, compreendendo minha intenção, e disse o nome da universidade que havia cursado.

Apesar dessas características, apenas recentemente apontadas como problemas, a exigência de "neutralidade" sempre foi um objetivo manifesto de promotores e inspetores do "mundo nuclear" na França.

Entretanto, a perspectiva de um Estado francês administrado por pessoas com capacidade de agir em função de uma "vontade geral", e não movidas por qualquer interesse particular, parece ter sido afetada pela forma como o governo reagiu ao acidente de Tchernobyl, destoando de outros governos europeus. Não só a imprensa francesa demorou a divulgar o acidente, ao contrário da alemã e da italiana, como na França não se estabeleceu qualquer medida "de proteção aos cidadãos", como a restrição ao consumo dos produtos agrícolas, a exemplo do que aconteceu em outros países da Europa.

Para culminar, houve uma declaração inábil que marcou indelevelmente o "mundo nuclear francês", dada por um professor que, na época, representava a entidade equivalente à atual Autoridade Nuclear. Segundo este "alto funcionário" do mundo nuclear, a nuvem radioativa proveniente da catástrofe teria parado antes de cruzar a fronteira da França. A imprecisão da informação evidenciou facilmente a implicação do Estado francês ao defender não apenas seu próprio programa nuclear, mas o mundo nuclear em si. A falta de neutralidade por parte das autoridades nucleares teve como conseqüência imediata a criação de um laboratório "independente", a CRIIRad (Commission de Recherche et d'Information Indépendantes sur la Radioactivité), além de várias démarches judiciais contra o funcionário em questão, sustentando a acusação de mentira de Estado, levadas à frente por associações ligadas ao meio ambiente. ${ }^{14}$

Esse incidente veio reacender a polarização gerada no momento de implantação das usinas nucleares entre "anti" e "pró", e que parece ser uma contradição inconciliável. As posições bem marcadas e muitas vezes defendidas com paixão são consideradas "ideológicas" e, por isso, nefastas à construção de instituições democráticas que supostamente pautam suas decisões por critérios "racionais" voltados para a defesa de um "bem comum". Foi neste 
sentido que a já citada subministra da Indústria, Nicole Fontaine, afirmou em seu pronunciamento na décima quinta conferência dos presidentes de CLI: "A questão nuclear deve ser abordada de maneira objetiva, sem tabus, sem idéias preconcebidas e sem ideologia". A demora na assinatura da lei sobre transparência nuclear também é explicada pela resistência de se criarem situações em que o debate "pró-anti" possa ser revivido em sua dimensão "passional" e "divisionista". Freqüentemente recorre-se à metáfora da "guerra" para se fazer alusão ao debate entre os "anti" e os "pró".

\section{Atribuições e embates da CLI}

As atribuições formais das CLI (troca de informações e acompanhamento do funcionamento da central nuclear) acabam na prática sendo ampliadas ou modificadas, de tal modo que é comum seus membros a definirem como um "mediador" entre a usina e a população em geral. Ela pode representar a usina para os habitantes, da mesma forma que leva suas opiniões até os engenheiros da central. Embora os atores sejam capazes de fazer do espaço aberto pela CLI um uso inesperado, e as expectativas atribuídas por cada membro à atuação da CLI possam apresentar nuances, há o estabelecimento de premissas comuns. Assim, todos concordam que as CLI devam ter "independência" de ação e que as informações sejam divulgadas com "neutralidade". Portanto, o binômio neutralidade/independência é visto como indispensável ao bom funcionamento da comissão.

A atribuição de neutralidade é destinada basicamente àquele que ocupe um lugar adequado, isto é, fora dos dois pólos "anti/pró"; a idéia de "neutro" equivale à de não estar sob a influência de uma opinião, de uma "ideologia", e eqüidistante dos pólos opostos. A independência da CLI é sobretudo não reproduzir acriticamente as informações recebidas pela EDF; mas de um modo geral, independência significa "desinteresse", ou melhor, ser "economicamente desinteressado", não estar sujeito a pressões econômicas.

Uma iniciativa dos participantes das CLI no cumprimento de suas funções formais é unir a idéia de "informação" àquela de "formação". Formados ou iniciados no saber nuclear podem alcançar boa compreensão do que está sendo dito pelos engenheiros e, importante, podem colocar perguntas pertinentes, distanciando-se de uma postura "acrítica" em relação às informações dadas pela central.

Embora a rapidez do movimento que associa seu papel de informação ao de formação varie de uma comissão para outra, a ANCLI incumbe-se de socializar tal perspectiva. Assim, as viagens de estudos, as reuniões e os colóquios que acontecem entre as assembléias, promovidos tanto pelas CLI quanto pela ANCLI, são oportunidades para os leigos (também chamados 
profanos) terem acesso a esse conhecimento restrito e abstrato e "se formarem". Os membros da CLI assumem então para si essa missão pedagógica, enfatizada por Callon et alii (2001) quanto a outras instâncias análogas.

Para garantir aquelas duas premissas, a CLI deve ser aberta, não sem dificuldade, à presença de militantes antinucleares em sua composição. Tal presença é condicionada à aceitação de não manifestarem idéias contrárias ao nuclear durante as assembléias, ficando seu papel restrito ao questionamento sobre mensurações e funcionamento do reator, já que a constituição de um espaço "independente" e "neutro" exige que se evite a discussão política interna. Essa assepsia é assegurada pelos presidentes, mesmo que eles tenham no passado defendido uma postura francamente crítica ou "anti" (como são, respectivamente, os casos do presidente da CLI de Nogent-surSeine e do presidente da CLI de Fessenheim).

Dois entrevistados que se definem como antinucleares disseram estar conscientes de que sua participação dá legitimidade às reuniões de suas respectivas CLI que, aceitando a presença dos "anti", podem se afirmar como espaço "neutro" ou, pelo menos, "aberto à pluralidade de visões". Mesmo que se sintam injustiçados pela democracia interna da comissão, reconhecem que durante as assembléias é possível ter acesso a informações que julgam importantes, além de, eventualmente, criarem algum fato político. Por exemplo, um membro reconhecido como "anti", da CLI de Fessenheim, apresentou uma carta na primeira assembléia de 2004 solicitando o fechamento da central; ele é francês, mora na Alemanha e pertence a uma organização "verde" muito "ativa". O presidente da comissão recusou a leitura da carta na reunião, afirmando não ser o lugar adequado para isso.

Em 2005, a primeira assembléia da CLI de Nogent realizou-se no dia do décimo nono aniversário do acidente nuclear de Tchernobyl, ocorrido em 26 de abril de 1986. Embora a data tenha sido lembrada por jornais franceses e pela televisão, que transmitiu programas de debates sobre o tema focalizando os problemas nacionais, além de reportagens sobre o acontecimento propriamente dito, durante a reunião nada se falou sobre o assunto. Não só a discussão "antipró" é evitada, como qualquer outra que se afaste do assunto técnico também o é. Na mesma assembléia, um sindicalista e empregado da usina, que não é membro da CLI, ali chegou com o propósito de ler e de distribuir uma carta, denunciando o que o sindicato que a assinava chamava de "falta de segurança na operação do reator" devido a demissões na central. O presidente não demorou a assinalar a impropriedade da atitude e desencorajou a discussão.

Os "anti" são em geral considerados como detentores de boa formação, pois sendo motivados pelo tema a partir de um gosto pessoal, e não por obrigações institucionais, já começam a participar da CLI "formados", 
com bom nível de conhecimento específico. Eles se sentem à vontade para criticar os engenheiros da EDF e colocar perguntas que exigem da empresa a exposição de um número suplementar de detalhes técnicos.

Em Nogent-sur-Seine, o "anti" que é membro da CLI pertence também ao Comitê Stop-Nogent, que foi criado no início da operação da Central, em 1984, por pessoas que moravam am Paris, portanto a $50 \mathrm{~km}$ da usina. Em entrevista, o maire e presidente da CLI de Nogent lamentou o fato de ter incidido sobre sua pequena cidade, na época da instalação da central, a "influência de Paris". ${ }^{15}$ Os parisienses que criaram o Comitê Stop-Nogent chegaram à cidade para fazer oposição. Logo depois do acidente de Tchernobyl, esse comitê rearticulou-se durante um período, arrefecendo sua atuação apenas alguns anos depois. Ele descreveu a atitude dos moradores daquela cidade como "passiva", mas mostrou que não foi uma reação unânime:

O Conselho Municipal que na época administrava a comuna [de Nogent-surSeine] foi favorável à instalação da usina. Eu ainda não tinha sido eleito na época. Mas uma parte da população foi contra. Houve manifestações. Os ecologistas, os verdes, chegaram de todos os lugares. Mas a maioria dos nogentais ... eles ficaram passivos. Eles não eram nem a favor nem contra; aqueles que eram contra eram antes os que vinham de fora.

Em seu cálculo, a maioria dos habitantes não se posicionou claramente contrária à implantação da central ; além disso, houve discordância, mesmo que de poucos moradores. Mas na narrativa, há preferência por enfatizar que as manifestações contrárias devem ser atribuídas aos forasteiros. Em artigo que escreveu na revista Déclic, substitui a palavra "passiva", que eventualmente pode ter uma conotação negativa, por "neutra" que, nesse contexto, tem uma acepção bastante positiva. Entretanto, diferindo da acepção atribuída à palavra no âmbito da CLI, a palavra "neutra" tem aqui significação bastante específica, querendo dizer "indiferença" ou ainda "aceitação" tácita: "Na época, a acolhida à central foi neutra e suscitou principalmente reações 'parisienses'". ${ }^{16}$

A retórica de se atribuir oposição a uma influência externa, dos vizinhos, sejam eles "verdes alemães" ou "parisienses", parece ser um mecanismo a mais de minimizar o confronto de opiniões contrárias tanto das cidades quanto do próprio território francês, tratando-se de Fessenheim. O maire e presidente da CLI de Nogent se preocupa ainda hoje em evitar que a influência, vinda de Paris e, em especial, do "anti" que freqüenta suas assembléias, atue sobre os nogentais, o que poderia desviar a discussão técnica para um debate político sobre a utilização da energia nuclear. 
Enquanto o papel de comunicação/informação/mediação da CLI passa a exigir formação técnica, também a perspectiva dos porta-vozes da EDF e da Autoridade Nuclear em relação às suas respectivas funções na CLI pode se alterar; o lugar de apresentação dos relatórios técnicos que apresentam é passível de ser visto também como um espaço para a criação de vínculos diretos. As assembléias da CLI possibilitam uma maior proximidade entre administradores municipais, demais habitantes e engenheiros da EDF, constituindo uma forma de humanizar/pessoalizar relações entre esses representantes. É no contato direto que se torna viável cultivar a confiança entre empresa e inspetores, de um lado, e moradores e maires, de outro. As instituições ganham rostos, personalidade e são capazes de inspirar confiabilidade, o que minora dificuldades de comunicação num eventual momento de crise.

Em caso de acidente, entretanto, a CLI não tem nenhuma função a cumprir, conforme ressaltam os técnicos da empresa e da Autoridade Nuclear, que é a primeira a ser comunicada em face de uma anormalidade. A Autoridade Nuclear (com sede em Paris, onde há uma sala de operação de crise) comunica então ao préfet e ao maire. Cabe ao primeiro desencadear o procedimento conveniente em situação de crise, sob a orientação dos técnicos. Mas não existe nem consenso nem total clareza entre os membros da CLI de que eles não tenham nenhum papel a cumprir em caso de acidente.

Sobre a atribuição das CLI no "acompanhamento dos impactos", há que se diferenciar dois tipos: o ambiental e o chamado impacto urbano. Este último refere-se às mudanças provocadas na cidade tanto no momento de sua implantação, quanto os decorrentes da chegada dos trabalhadores para as obras de construção dos prédios, e também, a cada 18 meses aproximadamente, quando há troca de combustível. Trata-se de um período em que se fazem vistorias nos sistemas da usina e, para tanto, a EDF contrata firmas, o que acarreta certo afluxo de trabalhadores para a cidade. Os "impactos urbanos" desses momentos de parada do reator são vistos normalmente como positivos, conforme comentário do presidente da CLI de Nogent-sur-Seine durante a primeira assembléia geral de 2005:

É nosso objetivo acompanhar os impactos da Central e, atualmente, pode-se considerar que os impactos sociais provenientes das paradas para troca de combustível são impactos positivos e os donos dos hotéis e comerciantes de Nogent e das redondezas ficam felizes.

A outra forma de impacto constitui-se das alterações provenientes de vazamentos de substâncias no ar, no solo e nos rios. Não só o controle de 
taxas de elementos radiativos é importante, mas também o de substâncias químicas que são utilizadas para a manutenção da Central, e que devem ser eliminadas segundo quantidades fixadas por agências nacionais e internacionais. O sucesso deste acompanhamento depende então de informações provenientes da Central, diferente do impacto urbano, visível e mensurável pela administração municipal.

Como os impactos sobre o meio ambiente se fazem através de medições bastante específicas e que demandam a presença de um perito, os membros da CLI vêem-se na posição de aceitar as medidas fornecidas pela usina sem capacidade de "visão crítica" sobre a informação recebida — ou de compará-las com outras medidas provenientes de diferentes peritos, escapando da escuta exclusiva do que dizem os engenheiros da EDF.

Assim como a tarefa de "informar com neutralidade" é considerada indissociável de um processo de formação dos participantes, a tarefa de acompanhar os impactos sobre o meio ambiente exige verificações autônomas e independentes realizadas pelas comissões. Surge então uma outra tarefa, a da contra-expertise, que possibilita a verificação de uma informação graças à comparação entre várias fontes. A CLI para "informar" deve, então, formar; e para "acompanhar", deve medir e comparar.

\section{A contra-expertise}

Os testes de contra-expertise normalmente se referem a verificações sobre a liberação de determinadas substâncias radioativas ou não. Isto é possível porque os limites fixados pelos cientistas, no caso de emissão de substâncias no meio-ambiente, são acatados por todos, incluindo os "anti" que tomam assento nas assembléias, mesmo que fora dali tenham a firme convicção de que a menor quantidade que seja expelida já é insuportável. Se houver discrepância entre o resultado oferecido pela EDF e o apresentado pelo laboratório escolhido para a realização da contra-expertise, a explicação pode estar na diferença de métodos de medição. Se ficar comprovado que a empresa está poluindo acima do permitido, ela deve alterar sua forma de produção e se adequar às normas.

Sendo as assembléias dedicadas à apresentação das taxas de substâncias emitidas pela usina, dos casos de acidentes de trabalho e dos resultados obtidos na produção elétrica, a ciência torna-se a linguagem privilegiada no interior das CLI. Seus participantes só podem levantar questões e enfrentar discussões se puderem decodificar tais cifras. O recurso à expertise e à contra-expertise é a base do "duelo verbal" (Elias 1997:262), passíveis de 
ocasionar um real confronto entre as informações divulgadas pela central nuclear e as que podem ser obtidas por outros laboratórios a pedido dos membros da CLI.

A CLI de Fessenheim, ao longo de sua existência, recorreu diversas vezes à contra-expertise, mas essa démarche não foi usual para a CLI de Nogent-sur-Seine. Esta Comissão fez sua primeira contra-expertise em 2004 apoiada pela da ANCLI que, para assegurar a possibilidade de utilização do recurso pelas comissões, firmou convênio com um laboratório estatal e criou seu próprio comitê científico para dar suporte às comissões locais. A contra-expertise requer dinheiro e em relação às questões nucleares só pôde ser feita após o surgimento dos primeiros laboratórios autodenominados independentes, a exemplo da já mencionada CRIIRad.

O recurso à contra-expertise como método de atuação explicita a desconfiança a respeito das medidas fornecidas pela EDF, ameaçando instalar certo mal-estar dentro da CLI. Porém, a preocupação da ANCLI em dar suporte às comissões para a realização de contra-expertise, organizando um comitê científico e buscando a formalização, através de uma lei, de um orçamento que viabilize materialmente os pedidos de estudo aos laboratórios, tende a conferir um caráter rotineiro ao que antes parecia evocar um conflito.

O segundo dos colóquios anuais promovidos pela ANCLI foi sobre o tema da contra-expertise. Um dos pontos importantes foi a assunção de que na impossibilidade de uma expertise "neutra" — já que todos os peritos estão ligados a alguma instituição - ou de uma informação "neutra", a saída é recorrer à expertise "plural" e também à informação "plural". Daí a importância de se lidar com várias visões e diversos métodos de mensuração. Afirmam que não há a perspectiva de confrontação entre, por exemplo, os peritos da EDF e os peritos independentes. Há a comparação entre mensurações que, para serem levadas em consideração, devem ter seus métodos explicitados, o que permitirá a compreensão de eventuais diferenças.

A prática da contra-expertise e sua aceitação pelos diversos atores denotam a disposição do governo francês e, mais especificamente do "mundo nuclear francês", de abrir esse universo à visitação pública e à interferência externa. Recentemente houve grandes mudanças institucionais no sentido de se reestruturarem os organismos ligados à inspeção nuclear e à radioproteção. Há certo consenso de que sobretudo a Autoridade Nuclear tem se mostrado bastante acessível para a divulgação de informações. Uma boa ilustração dessa "vontade de transparência", para usar uma expressão do campo, foi o relatório apresentado pelo inspetor da ASN sobre a Central de Nogent-sur-Seine na primeira assembléia da CLI de 2005. Depois da apresentação discretamente otimista da EDF sobre seu próprio desempenho ao longo do ano de 2004, 
uma avalanche de problemas técnicos foi despejada com tranqüilidade sobre a platéia pelo jovem inspetor, que fazia sua estréia na ocasião sob o olhar cúmplice de seu superior na Autoridade Nuclear, que também compunha a mesa. Assim que o inspetor terminou a sua exposição, o presidente da CLI falou: "Agradeço a intervenção do inspetor cuja sinceridade me deixou um pouco surpreso". E verbalizando habilmente o mal-estar sempre presente na busca de transparência sobre o que foi criado para viver encerrado entre grossas e indevassáveis paredes de concreto e aço, acrescentou: "Não é que a EDF não seja sincera, mas cada um tem o seu papel".

Se Mr. Ancelin tivesse apenas manifestado sua surpresa, ele estaria se afastando daquilo que garante a gestão da desconfiança, que é sua exposição de forma "civilizada" (Elias 1990), segundo uma etiqueta. Mas ele contextualiza seu sentimento justificando a EDF: "não é que ela não seja sincera", isto é, a assembléia não é o lugar para esse tipo de acusação. E continua: "cada um tem seu papel", em outras palavras, é sabido que há interesses contrários em jogo.

Se cada um tem o seu papel, seu interesse, quem pode ser "neutro" num campo profundamente marcado no plano ideológico pela oposição "anti-pró", mas que só reconhece como legítima a prática informada por uma neutralidade de princípios?

Nesse campo, cada membro considera a si próprio como "neutro": seja porque não tenha uma opinião formada sobre o assunto; seja porque acredite na capacidade de se libertar de convicções políticas para agir em função de algo mais geral; seja porque avalie não possuir convicção pessoal e sim certezas cientificamente comprovadas. Mas todos podem ter motivos para duvidar da neutralidade do outro e, ainda mais, da independência do outro.

A EDF pode ser percebida com desconfiança por ser um agente interessado na manutenção do lucro da empresa, portanto, nem independente, nem neutra. A EDF, por sua vez, considera que a exigência de produtividade não coloca em causa a segurança na operação da usina. Embora a produção não seja de sua competência, a Autoridade Nuclear também pode ser vista com desconfiança; como os engenheiros da EDF, seus profissionais são funcionários públicos e ligados ao Programa Nuclear Francês. Ouvi de um inspetor da Autoridade Nuclear, durante uma entrevista, que nem ele nem o presidente da Autoridade Nuclear consideram-se "pró", porque agem tecnicamente e não politicamente. Em outros termos, um "pró" poderia não ter suficiente neutralidade ou independência diante de pressões econômicas em determinada situação na qual se deve, por motivos de segurança, parar um reator. Ele considera que ser "pró" é adotar uma posição política inconveniente para o exercício da ciência e da técnica. 
Os administradores municipais e os políticos locais podem ser suspeitos de comportamento interessado, uma vez que dispõem do dinheiro que chega através de impostos pagos pela central graças à produção de energia.

Os "anti" são invariavelmente considerados "tendenciosos". Também laboratórios auto-intitulados "independentes", como a CRIIRad, são tidos como "anti" tanto por funcionários da EDF quanto pelos da Autoridade Nuclear. Isto não impede, entretanto, que todos considerem a prática da contra-expertise benéfica para a construção de um mundo nuclear "neutro", porque a pluralidade de visões assegura algumas referências para a manutenção da neutralidade, aqui entendida como transparência ou "vontade" de explicitação de suas premissas e intenções. Esta é oposta à "vontade de segredo", acusação endereçada à EDF, em uma assembléia da CLI, por um líder sindical, quando o representante da empresa não queria divulgar o calendário de operação da usina, alegando questões de segurança.

Se é difícil, conforme foi dito, estar neste campo sem ser identificado com um dos dois pólos, o esforço das lideranças da CLI é evitar a ruptura diante da contradição, recorrendo ao dispositivo da pluralidade. A princípio, não há má-fé, falsificação, ou mesmo uma só verdade. A pluralidade aplicada às informações técnicas e que partilham, portanto, do que é universal a ciência - pode colocar em concurso resultados diferentes, na medida em que esse confronto lhes parece livre do viés "político" ou "ideológico".

Boltanski e Thévenot (1991:26-27) chamam a atenção para o fato de as grandezas sociais, que são objeto da filosofia política, também fundamentarem os argumentos aos quais recorrem atores envolvidos num conflito, constituindo uma gramática do vínculo político. De forma previsível, valores que existem na base da concepção administrativa estatal na França estão igualmente em jogo nessas comissões. Este é o caso da referência a um compromisso em prol de uma coletividade (o bem comum e a vontade geral, de inspiração rousseauniana) que, naquilo que se refere às CLI, parece ser a própria unidade da sociedade francesa, ameaçada de rachar entre prós e anti. Outro exemplo é o da idéia de pluralidade (cujas raízes no plano da filosofia política remontam a Tocqueville), a qual vem passando por intenso processo de reelaboração tanto no contexto do socialismo, quanto no do neoliberalismo.

\section{A participação}

As possibilidades de rendimento político de uma instância criada para canalizar ou viabilizar a expressão dos cidadãos é sempre algo variável e imprevisível. Por isso, importantes trabalhos sobre este tema, como os de Jacques 
Defrance (1988), Huw Beynon (1999) e José Sergio Leite Lopes et alii (2004, 2006), buscam qualificar a "participação" ao invés de quantificá-la, tarefa esta que sairia inclusive do escopo de análise das ciências sociais.

Por serem classificadas por seus membros como instâncias de "acompanhamento", de "elucidação" ou de "troca de informações" — definição tímida em relação ao que pode acontecer na prática das CLI mais atuantes ou previdentes - pondero que tais associações podem ser tomadas também, de forma mais genérica, como canais de "participação", na medida em que permitem que setores da sociedade civil, $^{17}$ aqui entendida como esfera autônoma em relação ao mercado e ao Estado, tenham acesso a instâncias de decisão antes monopolizadas por este último.

Embora as fórmulas participativas, das quais as CLI são exemplo, sejam relativamente recentes, Callon, Lascoumes e Barthe, bem como alguns entrevistados, tecem críticas à maneira de implantação do Programa Nuclear Francês como se tivessem a expectativa de que canais semelhantes pudessem ter sido postos em prática nos idos anos de 1970 /1980.

Depois da Segunda Guerra Mundial, os programas nucleares conheceram grande impulso no mundo todo. Tanto a vertente civil quanto a militar foram desenvolvidas sem prévia consulta às populações concernidas. Hoje em dia, a ausência dessa consulta faz com que a implantação de fábricas e laboratórios de pesquisa seja referida como "antidemocrática", idéia manifestada pelos entrevistados: membros das CLI, cientistas "independentes" e também alguns dos próprios promotores das atividades nucleares na França. Outra constante nas entrevistas foi a importância atribuída às manifestações de Fessenheim para a criação das mencionadas comissões, que nascem então com o papel de reverter tal caráter, conforme disse um funcionário da diretoria da Autoridade Nuclear:

Na minha opinião, hein?, na minha opinião, a circular que cria as comissões surgiu porque o Programa Nuclear Francês, que compreende 19 Centrais, foi criado rapidamente e os franceses dizem que foi à la hussarde, ou seja, ninguém perguntou à população se ela estava de acordo. Foi assim: "Bem, a Central está aqui e vocês não têm nada a dizer". Então, em certo momento, e isso começou em Fessenheim, algumas pessoas fizeram greve de fome. Elas não queriam a Central. E elas fizeram a manifestação, a greve de fome, durante 10 dias. Então, as autoridades disseram: "Atenção, é preciso haver uma espécie de diálogo", então é necessário falar com os habitantes (Mr. Jacques Ibert).

Nessa mesma direção, o sociólogo Michel Callon, juntamente com outros pesquisadores, tece críticas mais contundentes: 
Durante décadas os engenheiros desenvolveram uma indústria nuclear que eles julgaram boa para o bem comum. Eles o fizeram de maneira secreta e dissimulada dentro de seus escritórios. Oh, não se tratava pura e simplesmente de defender interesses particulares disfarçados de interesse geral. Não se tratava de enriquecimento pessoal. Certo, uma vez que existem, os programas industriais e tecnológicos terminam por segregar interesses que não querem outra coisa a não ser o seguimento dos próprios programas e que eles sejam cada vez mais irreversíveis para que não exista força com poder suficiente para colocá-los em questão. Mas é injusto afirmar que esses homens de decisão, esses politécnicos que passaram pela escola de Minas ou de Pontes, fortemente solidários com seu corpo de pertencimento, só estavam movidos pelo ganho ou poder. Seu erro (grifo meu) já é suficientemente grave para que os condenemos por coisas que eles não cometeram. Eles simplesmente quiseram a felicidade do povo sem deixá-lo dizer uma palavra, sem convidá-lo para a mesa de discussão e negociação (Callon et alii 2001:154).

A ausência de um canal de participação é denominada "erro" por Callon et alii (2001), desmerecendo o fato de o programa nuclear ter obtido, por um lado, a consonância de diversos setores da sociedade francesa, tanto à direita como à esquerda, a exemplo de centrais sindicais, notadamente a CGT (cf. Hecht 1989; Bourrier 2004) e, por outro lado, ter enfrentado importantes manifestações contrárias — ver Touraine et alii (1980) e Pollak e Nelkin (1981) — as quais, entretanto, não tiveram êxito em paralisá-lo.

Luc Boltanski e Ève Chiapello analisam as transformações do capitalismo, evidenciando como este modo de produção é vitorioso ao conciliar o processo de acumulação de capital com um segundo, o de autocrítica, que permite eliminar práticas em desconformidade com o primeiro, sustentando assim sua credibilidade (Boltanski \& Chiapello 1999:66-67). Esta perspectiva nos mostra uma das dimensões que explicam a diferença entre os contextos da mobilização acontecida em Fessenheim (em 1977) e o da assinatura da circular que criou as CLI pelo governo socialista francês, eleito em 1981; trata-se de dois momentos distintos na relação com a crítica.

Ainda no referido trabalho, Boltanski e Chiapello caracterizam três ideologias de justificação do capitalismo que denominam "espíritos"; cada uma dessas conformações ideológicas supõe princípios de justiça que funcionam a partir de sete ordens de grandeza ou cidades, teoria inicialmente desenvolvida em De la justification, les économies de la grandeur (Boltanski \& Thévenot 1991), obra na qual os autores analisam seis das sete cidades. Como o exame da dinâmica das CLI aqui empreendido evidenciou, os embates nessas comissões estão referidos a três ordens de grandeza: a vontade geral (da cidade cívica); a 
eficácia científica (da cidade industrial); e a mediação (Boltanski \& Chiapello 1999:162) da cidade por projetos, específica do "terceiro espírito".

O terceiro espírito, ainda em formação, surge quando uma nova elite político-administrativa se impõe, em meados da década de 1980, e fórmulas de autogestão da esquerda socialista - esta passando naquela época, na França, da oposição a postos de responsabilidade - são incorporadas pelos administradores de empresa (Boltanski \& Chiapello 1999:283-285). Ainda para os autores, a recente mudança que engendra um novo espírito traz a ruptura entre os mundos cívico e industrial, cuja comunhão havia sido um importante pilar do processo de industrialização, baseando-se inclusive nas crenças no progresso, no futuro, na ciência, na técnica e nos benefícios da indústria (Boltanski \& Chiapello 1999:55).

Se acreditarmos que existiu, como querem Boltanski e Chiapello (1999), um "espírito" que justificou também de maneira ampla todo o processo de industrialização e seus "riscos", enfraqueceremos a hipótese de má intenção, defendida por Callon et alii (2001), e tornaremos possível o entendimento de como o que aconteceu de forma tão profícua em países democráticos pode ser hoje considerado autoritário. Então, a indignação de Callon et alii (2001), visível no texto acima, é bastante compreensível, mas pouco elucidativa das mudanças que ocorreram. Esse "novo espírito" valoriza e institucionaliza a "participação" de diversos setores da sociedade, o que aumenta a flexibilidade na incorporação e na resposta às críticas ao sistema capitalista.

Podemos então associar o surgimento jurídico das CLI à confluência dos vários fatores já levantados: uma indústria, cujos enguiços podem provocar catástrofes, cuja implantação esteve envolta numa aura de "segredo"; a existência de um poderoso lobby favorável à sua manutenção; um movimento contrário que se radicaliza com uma greve de fome; um governo que se apresenta sensível às demandas da sociedade; finalmente, um contexto político e econômico mais amplo caracterizado pela capacidade de adaptação em termos de autojustificação (e automanutenção) aprimorada mundialmente pelo capitalismo.

Após a assinatura da circular que criou as CLI, nem todas as cidades que hospedavam uma fábrica nuclear apressaram-se a compor uma CLI. Não foi o caso de Nogent-sur-Seine, que rapidamente organizou a sua comissão, nem tampouco o de Fessenheim, que já possuía uma. Aproximadamente duas décadas após a mencionada circular, surge a ANCLI, que amplia a capacidade de articulação e expressão dessas comissões, evidenciando que a prática das comissões pode então sair dos limites de sua definição jurídica graças às iniciativas de seus participantes.

Na primeira assembléia de 2005 da CLI de Nogent-sur-Seine, o presidente anunciou uma surpresa para os presentes. Tratava-se da possibilidade de con- 
tratação dos serviços de uma empresa de dispositivos de segurança. Em caso de urgência na central, os telefones de membros da CLI — escolhidos e cadastrados conforme a conveniência - receberiam ao mesmo tempo uma chamada de aviso alertando para alguma anormalidade que estivesse acontecendo na usina. Foi feito um teste durante a assembléia, tendo os vendedores do produto utilizado a lista de presença. Duas dezenas de celulares (incluindo o meu) tocaram ao mesmo tempo no meio da reunião, e uma mensagem avisando que era uma simulação foi ouvida por todos que atenderam seus telefones.

Até então, as fábricas da EDF espalhadas pela França e a direção da ASN em Paris, onde há a sala que coordena a ação em situações de crise, já tinham esse tipo de contato. Com aquela iniciativa da CLI, representantes de fora do "mundo nuclear" intentam aprimorar essa comunicação, integrando-se a ele também em caso de acidente. Aliás, essa preocupação parece já estar presente na própria composição oficial da CLI de Nogent, que inclui profissionais como os chefes dos bombeiros, da polícia, do serviço médico, da companhia de água, enfim, pessoas que ocupam postos-chave para a ação ágil em uma emergência, conforme anteriormente mencionado. Este fato é mais uma ilustração de que instâncias criadas com funções bem delimitadas podem, contudo, reformular sua atuação original.

Ao qualificar então o tipo de participação posta em prática no seio das CLI, é fácil assinalar que tal instância pode ser entendida, a partir do que foi exposto, como um meio de gestão da desconfiança (nutrida pela população para com a central) — necessidade suscitada pela já referida ruptura entre os mundos cívico e industrial — e de gestão do risco tecnológico (proporcionado pela central à circunvizinhança), papéis que obviamente não constam da circular.

\section{Considerações finais}

Defrance (1988) mostra que a audiência pública é uma forma de concertação que cria uma comunicação entre agentes em desacordo, sendo uma técnica de gestão de relações humanas utilizada em uma grande variedade de conflitos. Embora as audiências públicas sejam instrumentos que visem a um acontecimento específico, e as CLI sejam comissões permanentes, a comparação é válida na medida em que ambas se referem a conflitos. Só que as audiências são, ao menos no plano do discurso (Beynon 1999), um espaço para superação desses mesmos conflitos, enquanto as CLI, ao contrário, são espaços para a sua suspensão, congelando a contradição entre "anti" e "pró", desprovidos de poder decisório. Se as CLI tivessem sido criadas para o debate propriamente 
político da escolha pela energia nuclear, inúmeras especulações poderiam ser feitas a respeito de quais teriam sido os desdobramentos; porém, somente uma delas é passível de ser considerada realmente plausível: a França seria hoje um país diferente, porque já assim o seria no momento em que tivesse aceitado a discussão reclamada hoje por Callon et alii (2001).

Ao se suspender o debate político e ao se neutralizar a contradição no interior da CLI, viabilizam-se as tarefas definidas pela circular e engendramse maneiras de gerir a desconfiança. Nela, o que explicita a contradição ou a desconfiança deve ser apresentado de forma a não causar constrangimentos. Foi justamente com este intuito, isto é, imaginando descaracterizar a feição rebelde do título da Comissão de Vigilância de Fessenheim, que um de seus membros propôs, em uma assembléia de 2004, a mudança do nome para Comissão Local de Informação, alinhando-se a todas as outras comissões ligadas a centrais nucleares, criadas após a circular. Definir-se como "vigilante", e não como "interlocutor", numa troca de informações, sugere justamente a explicitação da relação de suspeição entre usina e moradores locais, evitada em outras comissões. A proposta de mudança de nome fracassou diante da oposição de componentes mais antigos, incluindo o próprio presidente, que participou, na década de 1970, do já inúmeras vezes referido movimento contra a instalação da central de Fessenheim. Essa CLS tem uma história especial da qual não quer se desfazer, mesmo mantendo em sua prática a acordada etiqueta (Leite Lopes et alii 2004) de desconfiarem cordialmente.

É importante notar que, com todos os esforços para se manter a desconfiança dentro de parâmetros cordiais, o surgimento dessas comissões altera significativamente um quadro anterior, em que o risco era considerado praticamente inexistente, ou plenamente justificado, pelos promotores da indústria nuclear, posturas que, embora distintas, podem ter efeitos semelhantes no que tange à implantação das centrais. A naturalização de um risco — ou seja, a sua não-problematização (Leite Lopes et alii 2004:227) — não se confunde com a sua justificação (cf. Boltanski \& Thévenot 1991). A naturalização torna-o invisível, mas a justificação confere-lhe identidade e limites, e às CLI é permitido o movimento de "desnaturalização" do risco (Leite Lopes et alii 2004:227). Em face do risco nomeado, podem ser ativas ou passivas. As primeiras não querem apenas ser uma extensão da empresa, uma audiência para seus relatórios; buscam o questionamento e a comparação de medidas, caminho encontrado para submeterem as informações da EDF à confrontação com outras.

Entretanto, as CLI ativas podem ainda ser pragmáticas e se organizarem de modo complacente com as necessidades da empresa em gerir o risco. Se no interior da CLI a EDF é colocada à prova, aí a empresa encontra possibilidade de eco para suas recomendações sobre segurança e prevenção, e também para 
evidenciar sua competência. Assim, esse canal de comunicação entre cidadãos e fábricas nucleares pode assumir a função de gestão do risco tecnológico, mesmo que isto não esteja previsto na circular. Se, por um lado, a CLI nomeia o risco, "desnaturalizando-o", por outro, ela o normaliza junto aos habitantes e aos políticos, incluindo-o no cotidiano, reelaborando sua funcionalidade, admitindo e verificando seus limites (Leite Lopes et alii 2004:228).

A CLI que investe na formação de seus membros assume um papel didático junto aos demais moradores; mas aí a linguagem já não é mais a científica. Num dos folhetos educativos/informativos distribuídos pela CLI de Nogent há, passo a passo, o que os cidadãos devem fazer em caso de emergência na central; e quesitos tais como tranqüilidade e autocontrole são indispensáveis. Os pais não deverão telefonar para as escolas, evitando o congestionamento das linhas telefônicas, nem a elas se dirigirem na expectativa de recuperar seus filhos: "Eles estão bem assistidos", explica num desenho a mãe sorridente ao pai que, hesitante, segura o telefone, numa sala de estar. Do lado de fora, através do vidro da janela avistam-se átomos que flutuam na atmosfera. A representação, que serve para indicar o perigo, também assegura a forma de proteção: "Faça o que se pede, tudo se resolverá" - é o que está implícito na mensagem.

Externamente à CLI, seus membros assumem a inserção do risco no dia-a-dia, trabalhando informações e posturas preventivas, estimulando a confiança da população nas autoridades. Internamente à CLI, estabelecem um compromisso que enfrente a contradição insuperável entre "anti" e "pró". No discurso, reafirmam a expectativa de neutralidade que todos sabem que pode ser traída pelos atores interessados. Na prática, despedem-se da neutralidade, esperando que cada um faça seu papel e recorrendo à pluralidade de visões e à contra-expertise. Ao perceberem a incongruência das racionalidades em jogo, superam o risco de cisão interna, de contaminação por posições políticas, opiniões e interesses particulares, e o fazem através de um compromisso pelo "bem comum", o "progresso", a unidade da sociedade francesa, tendo no horizonte um outro risco, de baixa probabilidade e de grande conseqüência, a ser monitorado.

Recebido em 30 de outubro de 2006

Aprovado em 12 de março de 2007

Gláucia Silva é professora da Universidade Federal Fluminense. E-mail: < glauciasil@terra.com.br>. 


\section{Notas}

· Agradeço a Afrânio Garcia e Alain Gras, que muito contribuíram para a minha bem-sucedida passagem pela academia francesa. Meu sincero reconhecimento a José Sergio Leite Lopes, pelo incentivo para investigar as comissões de informação francesas e também pela possibilidade de constante interlocução. Agradeço igualmente as preciosas contribuições de Márcia Leite (UERJ), Delma Neves (UFF) e Telma Camargo (UCGO).

${ }^{1}$ Elias (1990) analisa a mudança de costumes ocorrida na Europa quando da passagem da Idade Média para o Renascimento baseando-se nos manuais de etiqueta da época. Denominou essa mudança de "processo civilizador", que consistiu na naturalização e na internalização de comportamentos relativos à sociabilidade que, por sua vez, pressupunham o autocontrole das emoções e uma "etiqueta". Tornar-se "civilizado" implicava a adesão a esse novo código. José Sergio Leite Lopes (Leite Lopes et alii 2004:27-28) retomou a idéia para a análise de aspectos dos conflitos socioambientais. Refiro-me então às duas contribuições para afirmar que participar da CLI é submeter a expressão das desconfianças a determinados limites e modos; por gestão da desconfiança entendo a adoção de práticas através das quais ela pode ser manifestada e eventualmente sanada.

${ }^{2}$ Trata-se de Mr. Debord, um dos fundadores da Commission de Recherche et d'Information Indépendantes sur la Radioactivité - CRIIRad.

${ }^{3}$ Emissão: "Dois países mentiram sobre a catástrofe de Tchernobyl: a França e a Ucrânia", ART (Tv 5), de 25/04/2005.

${ }^{4}$ Électricité de France (Entreprise Nationale).

${ }^{5}$ Os funcionários do Estado francês que atuam no "mundo nuclear" civil grosso modo, nas centrais elétricas, centro de pesquisas e entidade fiscalizadora (Autoridade Nuclear) — recebem seu pagamento pelo Ministério da Indústria.

${ }^{6}$ A França é dividida em Regiões e estas em Departamentos. Cada Departamento tem uma prefeitura, onde reside o préfet. Em cada Departamento pode haver várias subprefeituras, conforme sua importância e tamanho.

${ }^{7}$ Circular Ministerial de 15 de dezembro de 1981, n 1632/SG.

${ }^{8}$ Anteriormente às CLI ligadas às instalações nucleares já existiam comissões junto a indústrias químicas classificadas Seveso, mas que, segundo opinião manifestada que não encontrou discordância em um colóquio da ANCLI, acabaram por se tornar extensões das empresas.

${ }^{9}$ Isto é, nove centros do Commissariat à l' Energie Atomique (CEA), centros de estocagem, de pesquisa e a base secreta de Valduc. 
10 "Déclic" é uma palavra que significa momento em que se toma consciência de alguma coisa, ou em que alguma máquina entra em funcionamento. Em português, clique.

${ }^{11}$ São reuniões anuais; pude assistir à décima quinta, ocorrida em 2003.

${ }^{12}$ Mas normalmente as assembléias contam com cerca de 40 pessoas.

${ }^{13}$ E certamente não poderia ser diferente, pois a subvenção vem da Autoridade Nuclear.

${ }^{14}$ Segundo Mr. Francis Sorin, da Société Française d'Énergie Nucléaire, o referido funcionário ganhou até então quatro processos de difamação. "Você deve evitar uma inquietação desmedida", disse Mr. Sorin, defendendo a intenção do professor ao se referir à nuvem radioativa, durante o já citado programa de televisão.

15 "Paris" torna-se uma alegoria: é à cidade inteira que se atribui a defesa das idéias contestatórias efetivamente sustentadas por grupos que lá se organizaram; talvez a fórmula evoque também os séculos de influência do centro político sobre a província.

${ }^{16}$ Este trecho faz parte do artigo intitulado "Information, proximité, neutralité par Gérard Ancelin — Président de la CLI de Nogent-sur-Seine" (Déclic — le magazine de l'Ancli, 2001, p. 4).

${ }^{17}$ Para uma excelente discussão sobre as diversas redefinições por que passou o conceito de sociedade civil, ver Costa (2002) e também o volume I de Sociedade civil e cidadania: a experiência do Viva-Rio (Miranda 1998). 


\section{Referências bibliográficas}

BECK, Ulrich. 1992a [1986]. Risk society. Towards a new modernity. London: Sage.

. 1992b. "From industrial society to risk society : questions of survival social structure and ecological enlightment". In: M. Featherstone (org.), Cultural theory and cultural change. Londres: Mike Featherstone. pp. 97-123. 1995 [1991]. Ecological enlightenment. Essays on the politics of the risk society. Amherst, Nova York: Humanity Books. . 2003 [2000]. Liberdade ou capitalismo. Ulrich Beck conversa com Johannes Willms. São Paulo: EdUNESP.

BEYNON, Huw. 1999. "Protesto ambiental e mudança social no Reino Unido". Mana. Estudos de Antropologia Social, 5(1):7-28.

BOLTANSKI, Luc \& CHIAPELLO, Ève. 1999. Le nouvel esprit du capitalisme. Paris: Gallimard;

. \& THÉVENOT, Laurent. 1991. De la justification. Les économies de la grandeur. Paris: Éditions Gallimard.

BOURDIEU, Pierre. 1982. A economia das trocas simbólicas. São Paulo: Editora Perspectiva.

BOURRIER, Mathilde. 1999. Le nucléaire à l'épreuve de l'organisation. Paris: PUF.

2004. Le risque organisationnel. Enjeux pour la connaissance sociologique. Manuscrit présenté en vue de l'obtention de l'habitation à diriger des recherches en sociologie. Université de Technologie de Compiègne.

CALLON, Michel; LASCOUMES, Pierre; BARTHE, Yannick. 2001. Agir dans un monde incertain. Essai sur la démocratie technique. Paris: Seuil. Col. Couleur des Idées.
CHATEAURAYNAUD, Francis \& TORNY, Didier. 1999. Les sombres précurseurs. Une sociologie pragmatique de l'alerte et du risque. Paris: Ed. de L'École des Hautes Études en Sciences Sociales.

CHIVA, Isac. 1970. "Imagination colletive et inconnu". In: Pouillon \& Maranda (orgs.), Échanges et communications. Paris: Mouton. pp.162-168.

COSTA, Sergio. 2002. As cores de Ercilia: esfera pública, democracia, configurações pós-nacionais. Belo Horizonte: UFMG.

Déclic - Le Magazine de l'Ancli (Association Nationale des Commissions Locales d'information), n.1, décembre 2000 .

Déclic - Le Magazine del'Ancli (Association Nationale des Commissions Locales d'information), n.2, septembre 2001.

DEFRANCE, Jacques. 1988. “Donner la parole. La construction d'une relation d'échange". Actes de la Recherche en Sciences Sociales, 73:52-66.

DOUGLAS, Mary \& WILDAWSKI, Aaron. 1982. Risk and culture: an essay on the selection of technical and environmental dangers. Berkeley: Univ. of California Press.

DOUGLAS, Mary. 1992. Risk and blame: essays in cultural theory. Londres: Routledge.

ELIAS, Norbert .1990. O processo civilizador. vol 1. Rio de Janeiro: Jorge Zahar Editor. . 1997. Os alemães. A luta pelo poder e a evolução do habitus nos séculos XIX e XX. Rio de Janeiro: Jorge Zahar Editor.

HECHT, Gabrielle. 1989. The radiance of France. Massachussets: University of Massachussets. 
LEITE LOPES, José Sérgio. 2006. "Audiência pública em Angra dos Reis: debate em torno do licenciamento de uma usina nuclear". In: Moacir Palmeira \& César Barreira (orgs.), Política no Brasil: visões de antropólogos. Rio de Janeiro: Relume Dumará / Núcleo de Antropologia da Política UFRJ. pp. 369-393. . ; ANTONAZ, Diana; PRADO, Rosane Manhães \& SILVA, Gláucia. 2000. "Naturalização e estranhamento: alguns aspectos da construção social da poluição ambiental em Itaguaí, Angra dos Reis e Volta Redonda, RJ". Cadernos IPPUR, XIV(1):181-196.

LEITE LOPES, José Sérgio; ANTONAZ, Diana; PRADO, Rosane Manhães \& SILVA, Gláucia (orgs.). 2004. A ambientalização dos conflitos sociais. Participação e controle público da poluição industrial. Rio de Janeiro: Relume Dumará/ Núcleo de Antropologia da Política - UFRJ.

MIRANDA, Napoleão. 1998. Sociedade civil e cidadania: a experiência do Viva-Rio. vol. 1. Tese de doutorado, IUPERJ, Rio de Janeiro.

POLLAK, Michael \& NELKIN, Dorothy. 1981. The atom besieged. Cambridge: MIT University Press.

SILVA, Gláucia. 1999a. Angra I e a melancolia de uma era. Um estudo sobre a construção social do risco. Niterói: EdUFF.

. 1999b. "Risco tecnológico e tradição: notas para uma antropologia do sofrimento". Antropolítica. Revista Contemporânea de Antropologia e Ciência Política, 7:57-73.

TOURAINE, Alain et alii. 1980. La prophétie anti-nucléaire. Paris: Seuil.

ZONABEND, Françoise. 1989. La presqu'île au nucléaire. Paris: Odile Jacob. 
Resumo

No artigo, pretendo demonstrar como funcionam as Comissões Locais de Informação (CLI) que foram criadas na França com a finalidade de possibilitar o contato entre representantes das instalações industriais nucleares e as populações concernidas, que assim podem acompanhar a operação dessas fábricas. Eu argumento que sua criação permite a gestão da desconfiança (nutrida pela população para com a central nuclear), e a gestão do risco tecnológico (proporcionado pela central à circunvizinhança), a partir de critérios eleitos por seus partícipes: "neutralidade", "independência" e "desinteresse" de ação. Tais critérios são por eles considerados fundamentais para que a comunicação entre empresa e cidadãos em geral possa acontecer com sucesso, num contexto marcado pela oposição (descrita muitas vezes como "guerra") entre os adeptos e promotores da indústria nuclear, de um lado, e os que se manifestam contrariamente a ela, de outro.

Palavras-chave: Conflitos sociais na França, Participação da população, Risco nuclear

\section{Abstract}

In this article, I examine the functioning of the Local Information Commissions (LICs) set up in France as a way of liaising between representatives of nuclear facilities and local populations, enabling the latter to monitor the operation of these plants. I argue that creation of the LICs allowed the management of both distrust (harboured by the population vis-à-vis the nuclear plants) and technological risk (posed by the plant to its neighbourhood) through the use of criteria selected by their participants: 'neutrality,' 'independence' and 'disinterested action.' These criteria are deemed fundamental in terms of the success of the communication between the company and the general public, especially in a context riven by the conflict (very often described as a 'war') between supporters and promoters of the nuclear industry and those campaigning against it.

Key words: Social conflicts in France, Public participation, Nuclear risk 